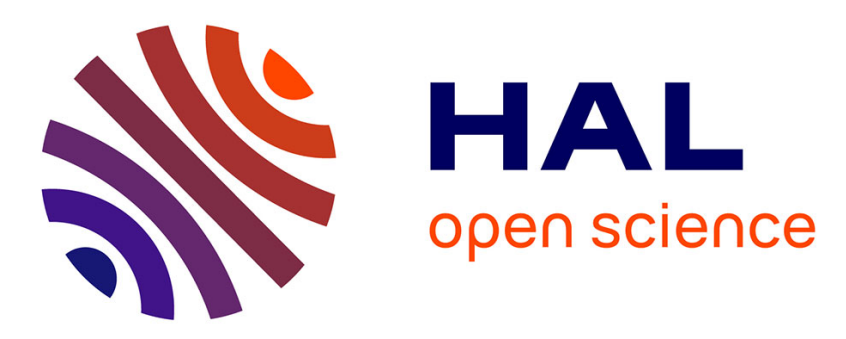

\title{
Susceptibility of autochthonous German Fraxinus excelsior clones to Hymenoscyphus pseudoalbidus is genetically determined
}

Rasmus Enderle, Aikaterini Nakou, Kristina Thomas, Berthold Metzler

\section{- To cite this version:}

Rasmus Enderle, Aikaterini Nakou, Kristina Thomas, Berthold Metzler. Susceptibility of autochthonous German Fraxinus excelsior clones to Hymenoscyphus pseudoalbidus is genetically determined. Annals of Forest Science, 2015, 72 (2), pp.183-193. 10.1007/s13595-014-0413-1 . hal01284165

\section{HAL Id: hal-01284165 \\ https://hal.science/hal-01284165}

Submitted on 7 Mar 2016

HAL is a multi-disciplinary open access archive for the deposit and dissemination of scientific research documents, whether they are published or not. The documents may come from teaching and research institutions in France or abroad, or from public or private research centers.
L'archive ouverte pluridisciplinaire HAL, est destinée au dépôt et à la diffusion de documents scientifiques de niveau recherche, publiés ou non, émanant des établissements d'enseignement et de recherche français ou étrangers, des laboratoires publics ou privés. 


\title{
Susceptibility of autochthonous German Fraxinus excelsior clones to Hymenoscyphus pseudoalbidus is genetically determined
}

\author{
Rasmus Enderle • Aikaterini Nakou • Kristina Thomas • \\ Berthold Metzler
}

Received: 4 March 2014 / Accepted: 10 July 2014 / Published online: 30 July 2014

(C) INRA and Springer-Verlag France 2014

\begin{abstract}
- Context It might be possible to establish a new generation of Fraxinus excelsior which is insusceptible towards ash dieback (agent: Hymenoscyphus pseudoalbidus) by efficient breeding. However, a considerable number of highly tolerant individuals which have the ability to pass on this trait to their progeny are needed.

- Aims The aim of this study was to identify the potential of provenances from southwestern Germany as a source of future selection for resistance or resistance breeding.

- Methods In July 2012 and 2013, ash dieback severity was scored by assessing the crown defoliation and the portion of epicormic shoots in the crowns in clonal seed orchards with a total of 1,726 ash trees in southwestern Germany.

- Results Ash dieback severity differed strongly between the orchards and the clones. Broad-sense heritability ranged from 0.18 to 0.55 for crown defoliation and from 0.48 to 0.58 for the portion of epicormic shoots between the orchards. Clones
\end{abstract}

\section{Handling Editor: Cécile Robin}

Contribution of the co-authors Rasmus Enderle: conception of the study, responsible for the data collection, data analyses except modelling and writing the manuscript.

Aikaterini Nakou: constructing and fitting the model.

Kristina Thomas: supervising the seed orchards of Rheinland-Pfalz and contributing to the data collection.

Berthold Metzler: supervising the study and contributing to the data collection.

R. Enderle $(\triangle) \cdot$ A. Nakou $\cdot$ B. Metzler

Department of Forest Protection, Forest Research Institute of

Baden-Wuerttemberg, Wonnhaldestrasse 4, 79100 Freiburg,

Germany

e-mail: rasmus.enderle@forst.bwl.de

K. Thomas

Research Institute for Forest Ecology and Forestry, Hauptstrasse 16, 67705 Trippstadt, Germany from nearby populations did not show differences in general levels of susceptibility.

- Conclusion The study highlights that there is high genetic variation in susceptibility and considerable genetic potential for resistance breeding in provenances from southwestern Germany.

Keywords Fraxinus excelsior · Hymenoscyphus pseudoalbidus · Ash dieback · Clonal seed orchards . Heritability $\cdot$ Tree breeding

\section{Introduction}

The ascomycete Hymenoscyphus pseudoalbidus (anamorph: Chalara fraxinea) is the causal agent of ash dieback (Kowalski 2006; Kowalski and Holdenrieder 2009; Queloz et al. 2011), a disease on Fraxinus excelsior L. which seriously endangers the sylvicultural utilization of this tree species in Europe. According to present knowledge, the pathogen is an invasive species in Europe which has been introduced from Far East Asia (Husson et al. 2011; McKinney et al. 2012; Zhao et al. 2012; Gross et al. 2014). The disease causes dieback of twigs, leading to defoliation of the crowns. Depending on individual tree vigour and susceptibility, the loss of twigs can be partially compensated for a certain period of time by formation of epicormic shoots.

Strong differences in susceptibility towards the disease have been observed between individual ash trees. A small fraction of trees seems to be partially resistant to the disease, which means that the resistance is of quantitative or partial nature (McKinney et al. 2011; Kjær et al. 2012; McKinney et al. 2012; McKinney et al. 2014). Studies on clones and families from Denmark, Lithuania, Austria and Sweden have shown that susceptibility is genetically determined (McKinney 
et al. 2011; Pliūra et al. 2011; Kirisits and Freinschlag 2012; Kjær et al. 2012; Stener 2013). Moreover, differences in ash dieback severity have been observed between provenances in Lithuania and Germany (Pliūra et al. 2011; Metzler et al. 2012; Enderle et al. 2013). Probably, evolutionary adaption and selection by foresters will slowly decrease the degree of susceptibility in the ash populations. Resistance breeding programmes may enable the establishment of a future generation of ashes of low susceptibility within a comparatively short period of time. However, a crucial point in resistance breeding is that a considerable number of individuals of low susceptibility need to be involved in order to preserve an adequate genetic diversity in the ash populations (Douglas et al. 2013; Pautasso et al. 2013). Genetic diversity is necessary if populations are to adapt on environmental changes such as new pests. In the case of $F$. excelsior, a particular future threat could be the emerald ash borer (Agrilus planipennis), a beetle which killed tens of millions of ash trees in North America (Poland and McCullough 2006) and is spreading westwards from the region of Moscow (Straw et al. 2013). Thus, it is very important to identify ash individuals of low susceptibility and of different provenances to get a better knowledge of the fraction of trees which could be suitable for breeding programmes.

An additional symptom associated with ash dieback is collar rot (Lygis et al. 2005; Skovsgaard et al. 2010; Bakys et al. 2011; Orlikowski et al. 2011; Husson et al. 2012; Enderle et al. 2013). H. pseudoalbidus is a colonizer of these basal lesions (Husson et al. 2012), but also, Armillaria spp. can often be detected on affected ash collars. According to present knowledge, the resistance to infections in the crown does not prevent from collar rot affection, although prevalence of this symptom is lesser in more resistant trees (Enderle et al. 2013).

Ash trees cover 4.2 and $1.0 \%$ of the total forest area in the German federal states Baden-Wuerttemberg and RheinlandPfalz, respectively (Federal Forest Inventory II, Kändler, personal communication). The summed up area of stands in which ash dieback led to noteworthy economic losses in 2012, as stated by regional forestry offices, was 633 ha in Rheinland-Pfalz and 11,451 ha in Baden-Wuerttemberg (Delb et al. 2013a, b).

In this study, ash dieback has been surveyed in four clonal seed orchards in Baden-Wuerttemberg and Rheinland-Pfalz to investigate (i) the general situation of ash dieback and its development, (ii) the interdependency between crown defoliation and the formation of epicormic shoots, (iii) differences in susceptibility between subprovenances of southwestern Germany and (iv) the heritability of susceptibility. The overall aim was to develop a basis of estimation regarding the potential of autochthonous provenances in seed orchards in southwestern Germany as a source of resistant seeds and of future resistance breeding.

\section{Material and methods}

\subsection{Investigated seed orchards}

Surveys were carried out in four different clonal seed orchards (Fig. 1). The properties of the seed orchards are presented in Table 1. The orchards comprise grafts of plus-trees which were selected for growth and stem quality prior to the outbreak of the disease. The plus-trees originated from different regions (Fig. 1, Table 1). However, according to the German forest species provenance system, all trees planted in one of the seed orchards, with the exception of Schorndorf, belong to the same provenance. This is why henceforth we refer to the regions of origins as subprovenances. Four subprovenances were present concurrently on the orchard of Kusel and Landstuhl (Fig. 1), but not the same genotypes of these subprovenances were used on the orchards. In average, there were 5.9 clones per subprovenance (min., 1 ; max., 26). In the orchard of Kusel, the ramets were planted in 13 blocks; in the orchard of Landstuhl, there were ten blocks. Because some of the trees had been removed or excluded from the analyses or had died, the blocks were not complete. In 2012, the mean number of genotypes per block was 57 (standard deviation, 15.7) in the orchard of Kusel and 38.2 (standard deviation, 4.4) in the orchard of Landstuhl.



Fig. 1 Locations of the seed orchards and regions of origin of the grafts (subprovenances) planted in the orchards 
Table 1 Properties of the investigated seed orchards in 2012

\begin{tabular}{|c|c|c|c|c|c|}
\hline Properties & Seed orchards & & & & Total \\
\hline Location & Emmendingen & Kusel & Landstuhl & Schorndorf & - \\
\hline Federal state & Baden-Wuerttemberg & Rheinland-Pfalz & Rheinland-Pfalz & Baden-Wuerttemberg & - \\
\hline Provenance $^{a}$ & 81107 & 81104 & 81104 & $81107 / 81108$ & - \\
\hline Year of establishment & 1995 & 1991/93 & 1992 & 1992 & - \\
\hline Design & Random & Random blocks & Random blocks & Random & - \\
\hline Spacing $[\mathrm{m} \times \mathrm{m}]$ & Flexible $(7.5 \times 10$ to $15 \times 15)$ & $7 \times 7$ & $7 \times 7$ & $7 \times 7$ & - \\
\hline Relative stand homogeneity & High & Medium & Low & Low & - \\
\hline Elevation ( $\mathrm{m}$ above sea level) & 200 & 400 & 400 & 400 & - \\
\hline Stand canopy cover & Open & Open & Open to dense & Open to dense & - \\
\hline Number of subprovenances & 17 & 11 & 10 & 9 & 43 \\
\hline Number of clones & 50 & 76 & 51 & 69 & 246 \\
\hline Status number $\left(N_{\mathrm{s}}\right)$ & 42.4 & 73.4 & 48.0 & 60.4 & - \\
\hline Sum of ramets & 218 & 741 & 382 & 385 & 1,726 \\
\hline
\end{tabular}

${ }^{a}$ Numbers according to the German forest species provenance system. 81104: Western German mountain area; 81107: Southern German hill and mountain area; 81108: Alps and alpine foothills

Figure 2 shows the distribution of the number of ramets per clone in the orchards. As a measure of the level of imbalance due to the unequal number of ramets per clone, the status number $N_{\mathrm{s}}$ as described by Kjær and Wellendorf (1997) and Lindgren and Mullin (1998) is presented in Table 1. All trees were examined for grafting success, and trees which exhibited indications of unsuccessful grafting, or trees of which the graft union was not clearly visible, were excluded from the survey.

\subsection{Data collection}

Data collection in the seed orchards took place in July and early August 2012. During this time of year, there is a maximum of foliage, as the formation of Lammas shoots is completed and premature leaf fall has not started. In the orchards of Kusel and Landstuhl, the surveys were repeated in July 2013. Because of the construction of a gas pipe in the orchard of Kusel, 42 ash trees had to be removed during the winter 2012/2013, and these trees were not included in the analyses of the data of 2013. The removals of trees led to a minimal reduction of the status number from 73.4 in 2012 to 73.2 in 2013.

Trees were divided into the following classes of crown defoliation: class $1=1-10 \%$, class $2=11-25 \%$, class $3=26-60 \%$ and class $4=61-99 \%$ crown defoliation. Trees without any visible symptoms of ash dieback were assigned to class 0 . Crown defoliation has often been used in recent studies to quantify the degree to which a tree is affected by the ash dieback disease (e.g. McKinney et al. 2011; Husson et al. 2012; Kirisits and Freinschlag 2012; Lenz et al. 2012). However, some trees were highly affected by ash dieback but showed a relatively low degree of crown defoliation due to extensive formation of epicormic shoots (Fig. 3). On the other hand, some trees were highly defoliated but showed only moderate symptoms of ash dieback. Thus, in order to record the degree of disease affection, trees were additionally divided into classes of the estimated portion of epicormic shoots in the crowns, using the same division of classes as for crown defoliation. We defined epicormic shoots in a broad sense, also including small side twigs that substitute for affected terminal shoots of branches. This could be accomplished easily by observing the crowns from opposite sides.

The assessment was carried out by the same person for the orchards in Emmendingen and Schorndorf, whereas three teams consisting of two people each assessed the trees in Kusel and Landstuhl. Prior to the

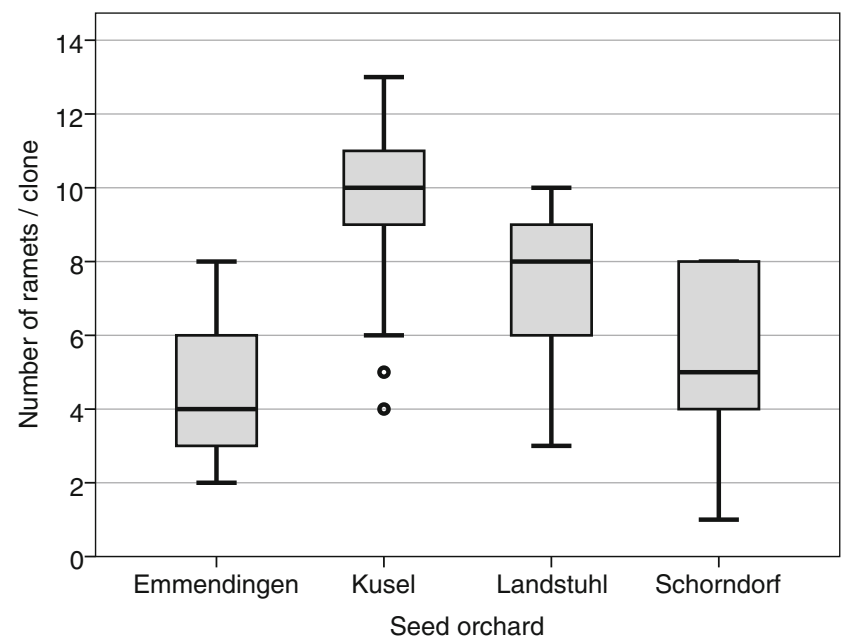

Fig. 2 Distribution of the number of ramets per clone on the four seed orchards 




Fig. 3 This tree on the seed orchard of Kusel is highly affected by ash dieback. The proportion of epicormic shoots in the living crown exceeds $60 \%$. However, due to the excessive formation of epicormic shoots, the inner crown is densely foliated and only the very outer rim is defoliated. The tree was assigned to crown defoliation class 2 (11-25\%)

survey, these teams synchronized assessment by rating about ten trees jointly with the person who assessed the other orchards in order to ensure the comparability of the data.

The individual health condition of the trees might be influenced by collar rots. In order to take this issue into account, every rootstock was examined for the presence or absence of collar rots. The trees showing collar rots were kept in the following analyses, as this symptom is closely connected with the ash dieback disease. No further diagnostics on the collar rots were conducted in order to remain the trees unaffected from artificial influences since further observations of the development of the disease in the seed orchards are foreseen.

\subsection{Statistical analyses}

In data analyses, the median of the range of the classes of crown defoliation and epicormic shoots was used (class 0 , $0 \%$; class $1,5 \%$; class $2,18 \%$; class $3,43 \%$; class $4,80 \%$ ). The traits for the orchards in Kusel and Landstuhl were analysed by applying the following generalized linear mixed model (GLMM) including Markov chain Monte
Carlo techniques using the MCMCglmm package for $\mathrm{R}$ (Hadfield 2010):

$Y_{\mathrm{ijk}}=\mu+c_{\mathrm{i}}+p_{\mathrm{j}}+b_{\mathrm{k}}+p_{\mathrm{j}}: b_{\mathrm{k}}+\varepsilon_{\mathrm{ijk}}$

where $Y_{\mathrm{ijk}}$ is the value of the variable (crown defoliation or epicormic shoots), $\mu$ is the grand mean, $c_{\mathrm{i}}$ is the random effect of the clone $\mathrm{i}$ that was nested in $p_{\mathrm{j}}$, the random effect of the subprovenance $\mathrm{j}, b_{\mathrm{k}}$ is the fixed effect of the block $\mathrm{k} ; p_{\mathrm{j}}: b_{\mathrm{k}}$ is the interaction effect of $p_{\mathrm{j}}$ and $b_{\mathrm{k}}$ and $\varepsilon_{\mathrm{ijk}}$ is the residual of the plot ijk. The model was run with 10,000 iterations. Based on the nature of the database at disposal (large number of data, rather complex structure), we choose an uninformative type of prior (default prior in the MCMCglmm Package). For both orchards and both years, the interaction effect of subprovenances and blocks was not significant. Thus, the model was run again without the interaction effect. The same model, but without the fixed effect of blocks $\left(b_{\mathrm{k}}\right)$, was applied for the other orchards, which were planted in a random design. Q-Q plots were examined to ensure that the distribution of the residuals was a close approximation of a normal distribution $\mathrm{N}\left(0, \sigma^{2}\right)$. The convergence of the Markov chains was verified by examining trace plots.

In order to estimate the degree to which the phenotypic variation is due to genetic factors, broad-sense heritability $\left(H^{2}\right)$ was calculated. The broad-sense heritability is the genetic variance divided by the phenotypic variance: $H^{2}=\sigma_{\mathrm{g}}^{2} / \sigma_{\mathrm{ph}}^{2}$ (e.g. Visscher et al. 2008). To obtain $\sigma_{\mathrm{g}}^{2}$, the variance and covariance components due to clones and the variance and covariance components due to subprovenances were added up. In order to assess how the phenotypic mean may change by adaption (evolvability), the coefficient of genetic variation $\left(\mathrm{CV}_{\mathrm{G}}\right)$ was calculated as the square root of $\sigma_{\mathrm{g}}^{2}$ divided by the total mean of the trait (Houle 1992). The genetic correlation between the two traits crown defoliation and portion of epicormic shoots (the genetic covariance divided by the square root of the product of the clonal variance components of the two traits) was estimated by computing the arithmetic means of the coefficients (Spearman's rho) obtained by correlation per clone. Genetic correlations between the years of data collection were computed in the same way.

\section{Results}

There were considerable differences in ash dieback severity between the different orchards. Ash dieback was less severe in the two orchards in Rheinland-Pfalz, Kusel and Landstuhl. 
a

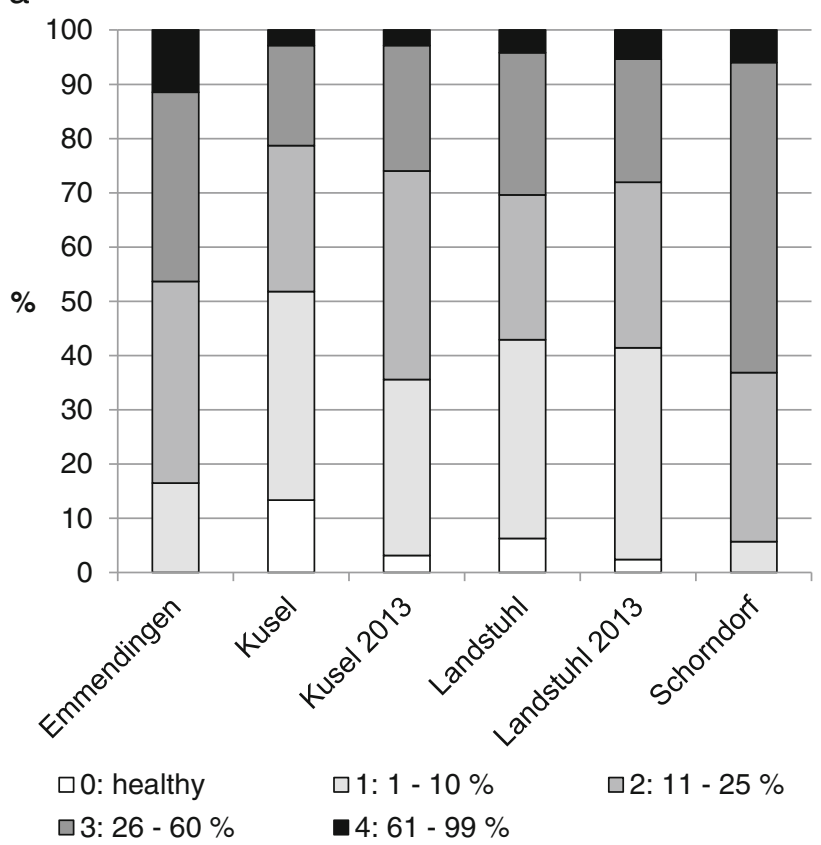

b

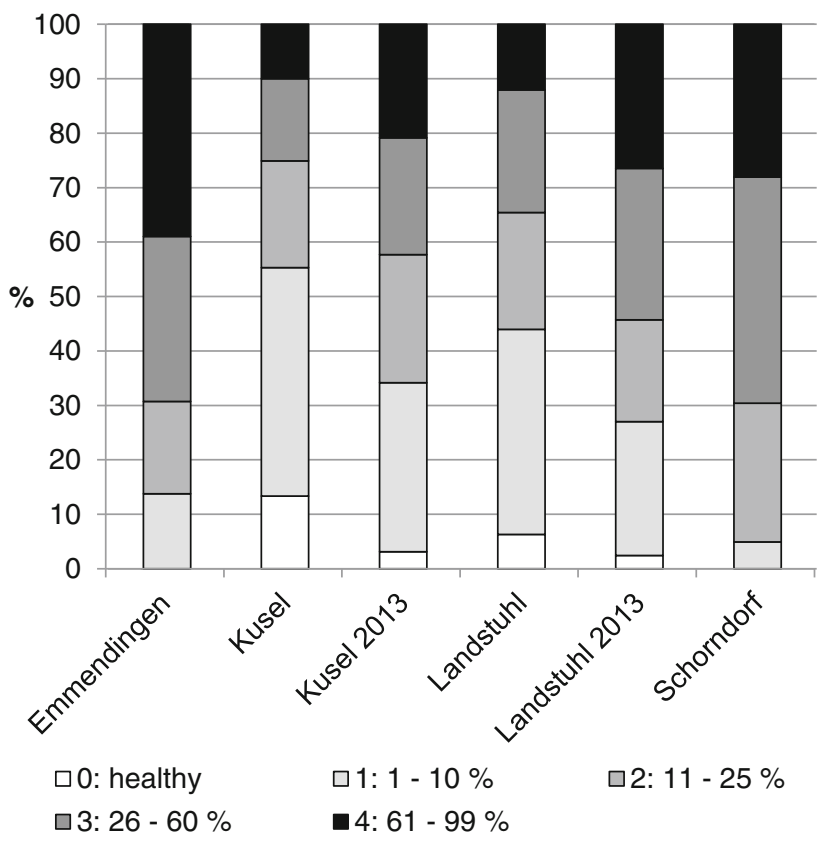

Fig. 4 Proportion of trees in classes of crown defoliation (a) and portion of epicormic shoots (b) for the four orchards in 2012 and 2013

Figure $4 \mathrm{a}, \mathrm{b}$ shows the proportion of trees in the classes of crown defoliation and epicormic shoots for the four orchards. In 2012, the proportion of trees in crown defoliation class 4 was rather small, ranging from $3.1 \%$ in Kusel to $11.5 \%$ in Emmendingen. In the orchards of Emmendingen and Schorndorf, there was no single completely healthy tree, whereas no symptoms could be detected on $5.9 \%$ of the trees in Landstuhl and $13.1 \%$ of the trees in Kusel. There were no completely symptomless clones. In total, the percentage of epicormic shoots was higher than that of crown defoliation (Fig. 4a, b; Table 2). The proportion of trees belonging to epicormic shoots class 4 ranged from $10.0 \%$ in Kusel to $39.0 \%$ in Emmendingen. The proportion of trees of epicormic shoots class 1 was quite similar to the proportion of trees of crown defoliation class 1. The comparison of the data from 2012 with the data from 2013 shows a substantial decrease of the proportion of symptomless trees. Additionally, the proportion of trees in the class 4 of epicormic shoots roughly doubled, whereas the proportion of trees in the class 4 of crown defoliation remained more or less constant (Fig. 4a, b).

The fixed effects of blocks in the orchards of Kusel and Landstuhl were significant in both years for both variables (see Appendix for detailed listed significance). Moreover, all variance components of the MCMCglmm were significant since the respective credible intervals are disjunct from zero (Table 2). However, compared to the variance due to clones and the residual variance, the response of the subprovenance effect was very small in all seed orchards. Broad-sense heritability $\left(H^{2}\right)$ and, in all cases but one, the $\mathrm{CV}_{\mathrm{G}}$ were generally higher for epicormic shoots than for crown defoliation. Heritability differed more for the latter variable between the orchards. From 2012 to 2013, the $H^{2}$ values for crown defoliation had not changed markedly. In contrast, heritability for portion of epicormic shoots slightly increased in the orchard of Kusel and slightly decreased in the orchard of Landstuhl. The $\mathrm{CV}_{\mathrm{G}}$ values for both traits decreased for both orchards.

On all seed orchards, crown defoliation was highly correlated with portion of epicormic shoots (Table 3). Coefficients were smaller for the seed orchards which were most affected by the disease (Tables 2 and 3). In accordance to this, the coefficients for 2012 were higher than the coefficients for 2013, when ash dieback became more severe. For all orchards but the orchard of Schorndorf, the coefficients of genetic correlation were smaller than the coefficients of the correlation of clonal means.

Moreover, there were high correlations between the years 2012 and 2013 for the two traits in the two orchards with repeated assessments (Table 4). The coefficients of genetic correlations were smaller than the coefficients obtained from correlation of clonal means and were approximately the same for the two traits. Genetic correlation was higher in the orchard of Landstuhl compared to the orchard of Kusel. The correlation of clonal means was slightly higher for the portion of epicormic shoots than for crown defoliation.

Prevalence of collar rots in 2012 was $3.6 \%$ in Kusel and $10.9 \%$ in Landstuhl. In Emmendingen and 
Table 2 Mean values, variance components and genetic estimates for the two traits crown defoliation and portion of epicormic shoots separated by orchards and years

\begin{tabular}{|c|c|c|c|c|c|c|}
\hline Location year & Emmendingen 2012 & Kusel 2012 & Kusel 2013 & Landstuhl 2012 & Landstuhl 2013 & Schorndorf 2012 \\
\hline \multicolumn{7}{|l|}{ Crown defoliation } \\
\hline Mean $[\%]$ & 31.7 & 17.0 & 20.8 & 21.2 & 21.5 & 35.2 \\
\hline$\sigma_{\mathrm{c}}^{2}$ & 203.3 & 128.6 & 101.5 & 94.6 & 93.2 & 56.0 \\
\hline $95 \% \mathrm{CI}\left(\sigma_{c}^{2}\right)$ & $72.3-365.5$ & $86.0-175.5$ & $65.6-144.1$ & $44.7-153.1$ & $49.0-144.8$ & $23.0-88.9$ \\
\hline$\sigma_{\mathrm{p}}^{2}$ & 124.8 & 0.5 & 1.3 & 9.5 & 0.0 & 0.1 \\
\hline $95 \% \mathrm{CI}\left(\sigma_{\mathrm{p}}^{2}\right)$ & $1.3 \mathrm{E}-05-370.8$ & $7.7 \mathrm{E}-17-0.215$ & $8.4 \mathrm{E}-17-8.072$ & $5.6 \mathrm{E}-14-55.75$ & $4.4 \mathrm{E}-17-3.8 \mathrm{E}-03$ & $6.7 \mathrm{E}-17-0.037$ \\
\hline$\sigma_{\varepsilon}^{2}$ & 263.5 & 195.6 & 187.0 & 284.4 & 252.9 & 246.7 \\
\hline $95 \% \mathrm{CI}\left(\sigma_{\varepsilon}^{2}\right)$ & $212.5-323.0$ & $174.9-216.2$ & $165.3-207.6$ & $239.9-329.8$ & $213.3-292.2$ & $208.1-282.5$ \\
\hline$H^{2}$ & 0.55 & 0.36 & 0.35 & 0.25 & 0.24 & 0.18 \\
\hline $95 \% \mathrm{CI}\left(H^{2}\right)$ & $0.38-0.71$ & $0.30-0.49$ & $0.26-0.45$ & $0.14-0.37$ & $0.17-0.38$ & $0.09-0.28$ \\
\hline $\mathrm{CV}_{\mathrm{G}}[\%]$ & 57.2 & 66.9 & 48.8 & 48.0 & 44.9 & 21.3 \\
\hline \multicolumn{7}{|c|}{ Portion of epicormic shoots } \\
\hline Mean [\%] & 48.0 & 20.1 & 31.7 & 25.1 & 37.8 & 45.1 \\
\hline$\sigma_{\mathrm{c}}^{2}$ & 479.0 & 281.8 & 468.8 & 318.5 & 421.5 & 293.3 \\
\hline $95 \% \mathrm{CI}\left(\sigma_{\mathrm{c}}^{2}\right)$ & $276.7-713.4$ & $182.2-389.1$ & $320.7-632.5$ & $186.6-476.1$ & $243.0-618.0$ & $179.7-419.2$ \\
\hline$\sigma_{\mathrm{p}}^{2}$ & 1.0 & 0.7 & 2.5 & 0.8 & 1.8 & 6.5 \\
\hline $95 \% \mathrm{CI}\left(\sigma_{\mathrm{p}}^{2}\right)$ & $1.2 \mathrm{E}-16-2.902$ & $8.7 \mathrm{E}-17-2.07$ & $7.6 \mathrm{E}-17-7.706$ & $1.0 \mathrm{E}-16-0.304$ & $4.5 \mathrm{E}-17-2.168$ & $4.5 \mathrm{E}-17-37.89$ \\
\hline$\sigma_{\varepsilon}^{2}$ & 369.2 & 294.2 & 341.1 & 238.3 & 405.2 & 316.6 \\
\hline $95 \% \mathrm{CI}\left(\sigma_{\varepsilon}^{2}\right)$ & $295.2-449.0$ & $263.4-326.7$ & $304.8-380.3$ & $205.2-276.4$ & $351.1-477.4$ & $267.1-365.6$ \\
\hline$H^{2}$ & 0.58 & 0.49 & 0.57 & 0.58 & 0.48 & 0.49 \\
\hline $95 \% \mathrm{CI}\left(H^{2}\right)$ & $0.43-0.69$ & $0.39-0.58$ & $0.49-0.66$ & $0.44-0.68$ & $0.39-0.63$ & $0.37-0.59$ \\
\hline $\mathrm{CV}_{\mathrm{G}}[\%]$ & 45.7 & 83.6 & 68.5 & 71.3 & 54.5 & 38.4 \\
\hline
\end{tabular}

$\sigma^{2}{ }_{\mathrm{c}}$ : variance component of clones, $\sigma_{\mathrm{p}}^{2}$ : variance component of subprovenances, $\sigma_{\varepsilon}^{2}$ : residual variance, $H^{2}:$ broad-sense heritability, $95 \% \mathrm{CI}()$ : respective credible interval, $\mathrm{CV}_{\mathrm{G}}$ : coefficient of genetic variation

Schorndorf, no collar rots could be detected. In 2013, collar rot prevalence increased to $8.2 \%$ in Kusel and $16.9 \%$ in Landstuhl. Differences in mean crown defoliation and mean portion of epicormic shoots between trees with and without collar rots are presented in Table 5. The difference in crown damage in 2013 was clearer when the trees which were already affected by collar rots in 2012 were compared to the unaffected individuals.

Table 3 Coefficients of genetic correlation $\left(r_{\mathrm{g}}\right)$ and correlation of clonal means ( $r_{\mathrm{c}}$, Spearman's rho, with $p$ values) between crown defoliation and portion of epicormic shoots

\begin{tabular}{lllll}
\hline Seed orchard & Year & $r_{\mathrm{g}}$ & $r_{\mathrm{c}}$ & $p$ \\
\hline Emmendingen & 2012 & 0.41 & 0.54 & $<0.001$ \\
Kusel & 2012 & 0.69 & 0.89 & $<0.001$ \\
Kusel & 2013 & 0.46 & 0.77 & $<0.001$ \\
Landstuhl & 2012 & 0.67 & 0.90 & $<0.001$ \\
Landstuhl & 2013 & 0.62 & 0.84 & $<0.001$ \\
Schorndorf & 2012 & 0.44 & 0.40 & $=0.001$ \\
\hline
\end{tabular}

\section{Discussion}

In the present study, the potential of seed orchards in southwestern Germany as a source of breeding for resistance against $H$. pseudoalbidus was analysed by surveying the two traits crown defoliation and portion of epicormic shoots. The study reports the current fraction of potentially resistant trees in four seed orchards, provides $H^{2}$ and $\mathrm{CV}_{\mathrm{G}}$ values of susceptibility and investigates the level of susceptibility of clones from different nearby populations. Further, it reveals novel insights in

Table 4 Coefficients of genetic correlation $\left(r_{\mathrm{g}}\right)$ and correlation of clonal means $\left(r_{\mathrm{c}}\right.$, Spearman's rho, with $p$ values) between the years 2012 and 2013 for the two traits in the two orchards with repeated assessments

\begin{tabular}{lllll}
\hline Seed orchard & Trait & $r_{\mathrm{g}}$ & $r_{\mathrm{c}}$ & $p$ \\
\hline Kusel & Crown defoliation & 0.32 & 0.80 & $<0.001$ \\
Landstuhl & Crown defoliation & 0.46 & 0.76 & $<0.001$ \\
Kusel & Portion of epicormic shoots & 0.30 & 0.91 & $<0.001$ \\
Landstuhl & Portion of epicormic shoots & 0.46 & 0.90 & $<0.001$
\end{tabular}


Table 5 Mean crown defoliation and portion of epicormic shoots in 2013 of collar rot affected and unaffected trees in 2012 and 2013 ( $p$ values: MannWhitney tests)

\begin{tabular}{llllrrr}
\hline & $\begin{array}{l}\text { Without collar rot } \\
2012\end{array}$ & With collar rot & $p$ & \multicolumn{2}{c}{$\begin{array}{l}\text { Without collar rot } \\
2013\end{array}$} & With collar rot \\
& & & & \\
\hline Mean crown defoliation [\%] & 21.1 & 25.9 & 0.048 & 21.2 & 23.0 \\
Mean portion of epicormic shoots [\%] & 33.6 & 43.5 & 0.003 & 33.5 & 39.9 \\
\hline
\end{tabular}

the interdependency between crown defoliation and the formation of epicormic shoots.

The $H^{2}$ and $\mathrm{CV}_{\mathrm{G}}$ values (Table 2) indicate a relative strong genetic determinism of susceptibility to ash dieback in southwestern German populations. Possibly, the $H^{2}$ values of the present study are even to a small part underestimated, as it cannot be guaranteed that the upper part of all trees consisted of the scion due to grafting mistakes or resprouting of rootstocks. However, we believe that wrong genotype affiliation, if at all, had a marginal influence on the genetic estimates in this study since the grafting success was thoroughly examined several times during the first growing seasons of the orchards, and all trees which exhibited indications of unsuccessful grafting during the survey, i.e. when the graft union was not clearly visible, were excluded from the analyses. Moreover, the results of the present study are quite in agreement to former studies from northern Europe. McKinney et al. (2011) scored damage due to ash dieback by assessing the percentage of loss of crown foliage, which is comparable to crown defoliation, over a time of 3 years in two stands. They reported $H^{2}$ values ranging from 0.25 to 0.54 and $\mathrm{CV}_{\mathrm{G}}$ values ranging from 38 to $87 \%$. From progeny tests in Denmark and Lithuania, quite similar results were reported for narrow-sense heritability $\left(h^{2}\right)$, ranging from 0.37 to 0.52 and from 0.40 to 0.49 , and for additive coefficients of variation $\left(\mathrm{CV}_{\mathrm{A}}\right)$, ranging from 37 to $61 \%$ and from 30 to $39 \%$ (Pliūra et al. 2011; Kjær et al. 2012). Results of a Swedish study on two sites revealed $H^{2}$ values ranging from 0.07 to 0.57 and $\mathrm{CV}_{\mathrm{G}}$ values ranging from 17 to $55 \%$, but these values are not directly comparable since they were calculated from ordinal data of ash dieback damage in different parts of the crowns (Stener 2013). As in the former studies (McKinney et al. 2011; Pliūra et al. 2011; Kirisits and Freinschlag 2012; Kjær et al. 2012; Stener 2013), no clone was completely unaffected. This confirms the suggestion that there is no genetically determined total resistance, although some genotypes exhibit a very low degree of susceptibility against ash dieback (Stener 2013). The observed decrease in the $\mathrm{CV}_{\mathrm{G}}$ values from 2012 to 2013 can be explained by the increase of the mean of the traits. Slight annual fluctuations of heritability could also be detected in other studies (McKinney et al. 2011; Kjær et al. 2012; Stener 2013).

Previous studies revealed high correlations between crown defoliation and disease intensity (Metzler et al. 2012; Enderle et al. 2013). However, other reasons for defoliation, such as abiotic factors, can also be important. Moreover, vigorous trees can countervail the loss of twigs as a result of ash dieback by forming epicormic shoots (Fig. 3). Thus, crown defoliation depends to a considerable degree on stand properties and micro-location and is rather an indicator of overall tree vigour than of susceptibility to ash dieback. This is why we believe that the portion of epicormic shoots in the crown, as defined in Section 2.2, is a better indicator of disease infection or susceptibility. Assessing the portion of epicormic shoots was not more time-consuming (after some time of practice) than assessing the crown defoliation. Although epicormic shoots are positively correlated with crown defoliation (Table 3 ), there are considerable differences in total values as well as in the estimates of $H^{2}$ and variance components (Table 2). The $H^{2}$ value for crown defoliation was highest in the orchard with the most homogenous stand conditions and considerably smaller in the orchards of relatively low stand homogeneity (Tables 1 and 2). This reflects the influence of the environment on the phenotype. The $H^{2}$ values for portion of epicormic shoots differ less between the orchards, indicating that the environment has less influence on this trait.

Assuming that the portion of epicormic shoots is an indicator of susceptibility and crown defoliation is an indicator of overall tree vigour, the positive correlations between the two traits imply that more susceptible trees are less vigorous and/or that trees of lesser vigour are more susceptible. The coefficients of genetic correlations and correlations from clonal means between the traits were higher on the orchards of relative low disease severity (Table 2 and 3 and Fig. 4), indicating that the interdependency between the two traits becomes lesser with increasing disease severity. The coefficients of genetic correlations were, in all orchards but the orchard of Schorndorf, smaller than the coefficients of correlations from clonal means. Apparently, 
the interdependency between the traits is only partly due to genetic causes.

The highly significant correlations of clonal means between the years for crown defoliation and portion of epicormic shoots (Table 4) show that the relative rank in the level of susceptibility of the clones was more or less stable over the years, although the total values of these traits increased. This is in agreement with a Danish study, where crown damage was surveyed over a period of 3 years (McKinney et al. 2011). The genetic correlations between the years confirm this result, although they were smaller than the correlations of clonal means (Table 4).

The subprovenances in the orchards of the present study are spatially not far apart from each other (Fig. 1). In the model, the influence of the subprovenances was significant, but very small. Thus, susceptibility to ash dieback seems to not be determined by subprovenances of closely located origins. However, differences in susceptibility were detected in a provenance trial between provenances from southern Germany which differ more in their geographic origin (Enderle et al. 2013). Pliūra et al. (2011) reported differences in susceptibility between Lithuanian and western European provenances, which they traced back to processes of adaption which had already commenced in the Lithuanian populations.

As expected, our data indicates a rapid increase of disease severity over time (Fig. 4). The number of trees without visible symptoms declined drastically, which could also be observed on other study sites in southwestern Germany. Apparently, new infections on hitherto healthy trees occur even after several years of strong infection pressure (Enderle et al. 2013), which complicate the estimation of the fraction of highly resistant individuals. However, a relative low degree of susceptibility can be assumed for the trees which have remained healthy for several years.

Ash dieback was considerably less severe in the orchards in Rheinland-Pfalz compared to the orchards in Baden-Wuerttemberg (Fig. 4). Since ashes and ash dieback are not as omnipresent here compared to Baden-Württemberg, there was probably less infection pressure on these sites and consequently lower disease incidence. In 2010, the area affected by ash dieback was 5 ha in Rheinland-Pfalz and 2,505 ha in BadenWürttemberg (Schröter et al. 2010a, b), so it seems that ash dieback was present earlier in Baden-Württemberg. Mean crown defoliation on four different sites of a provenance trial in Baden-Wuerttemberg ranged from 22 to $53 \%$ in 2011 (Metzler et al. 2012), which is in agreement to the results of this study.

The data suggest that collar rot-affected trees are more defoliated and have a higher portion of epicormic shoots than trees without collar rot, although the difference in crown defoliation in 2013 was not significant (Table 5). This might be due to reduced tree vigour in collar rot-affected trees. The difference in crown damage in 2013 was clearer when the trees which were already affected by collar rots in 2012 were compared to the unaffected individuals, indicating that the influence of collar rots increases with time. In another study, no influence of collar rots on radial increment could be detected, possibly because the phenomenon of collar rots was too recent to already have a measurable impact (Enderle et al. 2013). The following aspects complicate the interpretation of the present results: (i) the age of the necroses is unknown (although it appears likely that necroses formation took place within the last 4 or 5 years), (ii) the total lesion sizes and their extent in relationship to the diameter of the stems are unknown and (iii) the tissues of the crowns and of the trunk collars do not belong to the same genotype. Thus, we would like to refrain from drawing further conclusions from these results.

The present study shows that there is high genetic variation in susceptibility to ash dieback in the assessed clones. It highlights that there is a considerable genetic potential for future breeding for resistance in provenances of southwestern Germany. However, it is necessary to monitor the development of ash dieback in the next years to figure out if clones that appear resistant to $H$. pseudoalbidus at the moment will prove to stay unaffected over a longer period of time. The proportion of trees without any visible symptoms (class 0 ) or with only a small portion of epicormic shoots (class 1) is decreasing (Fig. 4). However, foresters are asked to preserve sound looking ash individuals in the forests (Metzler et al. 2013). Moreover, strong regeneration (up to 100,000 saplings/ha (Roloff and Pietzarka 1997)) is characteristic to $F$. excelsior, raising hope that a sufficient number of highly resistant trees will be available. Under this condition, we assume that it will be possible to establish an autochthonous ash generation with adequate genetic diversity and a high degree of resistance by conventional selection or, much faster, by tree breeding.

Acknowledgments Our thanks go to the Research Institute for Forest Ecology and Forestry of Rheinland-Pfalz for the kind support during the assessments and for providing their seed orchards. For their help during the surveys, we thank Johanna Bußkamp, Jonas Wehrle, Ricardo Rivero, Robert Krämer, Martina Stabel, Dietmar Weber and particularly Hermann Schott, who had good ideas for the development of the disease severity scoring system. We are grateful to Dr. Franziska Peters for revising the English and to anonymous reviewers for valuable suggestions improving the manuscript.

Funding The study was funded by the Forest Research Institute of Baden-Wuerttemberg. 


\section{Appendix 1}

Table 6 Significance of the fixed effect of blocks for crown defoliation and epicormic shoots and for the orchards of Kusel and Landstuhl in the 2 years of observation

\begin{tabular}{|c|c|c|c|c|c|c|c|c|c|c|}
\hline \multirow[t]{2}{*}{ Site } & \multirow[t]{2}{*}{ Year } & \multirow[t]{2}{*}{ Block } & \multicolumn{4}{|c|}{ Crown defoliation } & \multicolumn{4}{|c|}{ Epicormic shoots } \\
\hline & & & post.mean & $1-95 \% \mathrm{CI}$ & $\mathrm{u}-95 \% \mathrm{CI}$ & pMCMC & post.mean & $1-95 \% \mathrm{CI}$ & $\mathrm{u}-95 \% \mathrm{CI}$ & pMCMC \\
\hline \multirow[t]{13}{*}{ Kusel } & \multirow[t]{13}{*}{2012} & Intercept & 30.3 & 21.8 & 38.9 & $<0.001$ & 40.5 & 28.7 & 51.6 & $<0.001$ \\
\hline & & Block 2 & -13.2 & -21.9 & -4.7 & 0.006 & -15.5 & -26.7 & -3.2 & 0.016 \\
\hline & & Block 3 & -11 & -19.8 & -2.1 & 0.014 & -15.9 & -27.5 & -4.4 & 0.008 \\
\hline & & Block 4 & -6 & -14.7 & 3.3 & 0.22 & -8.1 & -20.6 & 3.5 & 0.182 \\
\hline & & Block 5 & -7.1 & -16.8 & 1.4 & 0.128 & -14.6 & -26.9 & -3.2 & 0.02 \\
\hline & & Block 6 & -11 & -20 & -2.5 & 0.022 & -20.8 & -34.2 & -9.9 & 0.002 \\
\hline & & Block 7 & -12.6 & -21.8 & -4.1 & 0.008 & -25.8 & -37 & -13.7 & $<0.001$ \\
\hline & & Block 8 & -14.1 & -24.4 & -6 & $<0.001$ & -21.9 & -33.4 & -9.4 & 0.002 \\
\hline & & Block 9 & -14.1 & -23.2 & -4.7 & $<0.001$ & -23.8 & -36.8 & -12.6 & 0.002 \\
\hline & & Block 10 & -21.7 & -30.4 & -13 & $<0.001$ & -28.6 & -41.1 & -17.7 & $<0.001$ \\
\hline & & Block 11 & -19.3 & -28 & -9.3 & $<0.001$ & -26.4 & -38.7 & -14.8 & $<0.001$ \\
\hline & & Block 12 & -21 & -29.9 & -11.4 & $<0.001$ & -28 & -39.3 & -15.5 & $<0.001$ \\
\hline & & Block 13 & -17.7 & -26.7 & -8.1 & $<0.001$ & -28.3 & -39.6 & -15.4 & $<0.001$ \\
\hline \multirow[t]{13}{*}{ Kusel } & \multirow[t]{13}{*}{2013} & Intercept & 37.2 & 28.6 & 44.6 & $<0.001$ & 38.8 & 27.6 & 51.4 & $<0.001$ \\
\hline & & Block 2 & -14.9 & -23 & -6.2 & $<0.001$ & -10.4 & -23.7 & 0.8 & 0.078 \\
\hline & & Block 3 & -16.7 & -25.7 & -7.7 & $<0.001$ & -4 & -16.3 & 7.7 & 0.518 \\
\hline & & Block 4 & -16.6 & -24.8 & -7.8 & $<0.001$ & -9.2 & -21.1 & 2.7 & 0.128 \\
\hline & & Block 5 & -6.5 & -14.8 & 2.6 & 0.138 & 2.7 & -9.9 & 14.6 & 0.64 \\
\hline & & Block 6 & -18.4 & -26.9 & -9.8 & $<0.001$ & -5.1 & -17.4 & 6.6 & 0.414 \\
\hline & & Block 7 & -10.6 & -19.7 & -2 & 0.02 & -2.1 & -15.7 & 9 & 0.73 \\
\hline & & Block 8 & -14.1 & -22.2 & -4.4 & $<0.001$ & -4.8 & -16.9 & 7 & 0.446 \\
\hline & & Block 9 & -10.9 & -19.9 & -2.4 & 0.02 & -6.6 & -18.2 & 5.9 & 0.294 \\
\hline & & Block 10 & -20.9 & -29.8 & -12.2 & $<0.001$ & -18.3 & -30.9 & -6.9 & 0.004 \\
\hline & & Block 11 & -26.8 & -35.2 & -18 & $<0.001$ & -16.1 & -27.5 & -3.8 & 0.01 \\
\hline & & Block 12 & -23.5 & -32.9 & -15.1 & $<0.001$ & -10.8 & -25.9 & -0.2 & 0.078 \\
\hline & & Block 13 & -22 & -30.4 & -12.8 & $<0.001$ & -7.6 & -19.6 & 4.1 & 0.198 \\
\hline \multirow[t]{10}{*}{ Landstuhl } & \multirow[t]{10}{*}{2012} & Intercept & 12.7 & 6.7 & 19.6 & $<0.001$ & 10.1 & 3.8 & 17.2 & 0.002 \\
\hline & & Block 2 & 14.5 & 7.1 & 21.4 & $<0.001$ & 9.2 & 2.6 & 15.1 & 0.01 \\
\hline & & Block 3 & 4.4 & -3.5 & 10.5 & 0.262 & 0.7 & -5.6 & 7.4 & 0.846 \\
\hline & & Block 4 & 4.1 & -3.1 & 11.3 & 0.294 & 21.6 & 14.2 & 28.1 & $<0.001$ \\
\hline & & Block 5 & 6.1 & -1.7 & 13.8 & 0.13 & 16 & 8.8 & 23.1 & $<0.001$ \\
\hline & & Block 6 & 15.9 & 8.3 & 23 & $<0.001$ & 29.3 & 22.7 & 36.3 & $<0.001$ \\
\hline & & Block 7 & 8.4 & 1.7 & 15.8 & 0.026 & 14.8 & 8.2 & 21.1 & $<0.001$ \\
\hline & & Block 8 & 9.6 & 2 & 16.6 & 0.01 & 12 & 6.1 & 19.3 & $<0.001$ \\
\hline & & Block 9 & 10.7 & 2.8 & 18.3 & 0.004 & 25 & 17.7 & 32.4 & $<0.001$ \\
\hline & & Block 10 & 14.8 & 7.8 & 23.3 & $<0.001$ & 19.3 & 12.7 & 26.3 & $<0.001$ \\
\hline \multirow[t]{6}{*}{ Landstuhl } & \multirow[t]{6}{*}{2013} & Intercept & 8.3 & 3.1 & 13.9 & 0.002 & 21.3 & 13.6 & 29.3 & $<0.001$ \\
\hline & & Block 2 & 9.3 & 2.3 & 15.9 & 0.014 & 17.8 & 8.1 & 26.4 & $<0.001$ \\
\hline & & Block 3 & 5.3 & -2.2 & 12.1 & 0.146 & 10.4 & 0.9 & 18.7 & 0.012 \\
\hline & & Block 4 & 18 & 11.2 & 25.7 & $<0.001$ & 20.2 & 11.2 & 29.2 & $<0.001$ \\
\hline & & Block 5 & 7.2 & -0.6 & 14.4 & 0.074 & 12.9 & 2.9 & 21.9 & 0.014 \\
\hline & & Block 6 & 31.5 & 24.2 & 37.6 & $<0.001$ & 24.9 & 15.8 & 34.1 & $<0.001$ \\
\hline
\end{tabular}


Table 6 (continued)

\begin{tabular}{|c|c|c|c|c|c|c|c|c|c|c|}
\hline \multirow[t]{2}{*}{ Site } & \multirow[t]{2}{*}{ Year } & \multirow[t]{2}{*}{ Block } & \multicolumn{4}{|c|}{ Crown defoliation } & \multicolumn{4}{|c|}{ Epicormic shoots } \\
\hline & & & post.mean & $1-95 \% \mathrm{CI}$ & $\mathrm{u}-95 \% \mathrm{CI}$ & pMCMC & post.mean & $1-95 \% \mathrm{CI}$ & $\mathrm{u}-95 \% \mathrm{CI}$ & pMCMC \\
\hline & & Block 7 & 20.6 & 13.6 & 27.4 & $<0.001$ & 18.1 & 9 & 26.7 & $<0.001$ \\
\hline & & Block 8 & 14.3 & 7.5 & 21.3 & $<0.001$ & 14.8 & 5.6 & 22.8 & $<0.001$ \\
\hline & & Block 9 & 7.3 & 0.9 & 15.2 & 0.046 & 26.3 & 16.6 & 36.3 & $<0.001$ \\
\hline & & Block 10 & 14.3 & 6.9 & 21.3 & 0.002 & 15.4 & 6 & 24.4 & 0.002 \\
\hline
\end{tabular}

post.mean estimated mean of the posterior distribution, $l-95 \% C I$ lower $95 \%$ credible interval, $u-95 \% C I$ upper $95 \%$ credible interval

\section{References}

Bakys R, Vasiliauskas A, Ihrmark K, Stenlid J, Menkis A, Vasaitis R (2011) Root rot, associated fungi and their impact on health condition of declining Fraxinus excelsior stands in Lithuania. Scand J For Res 26:128-135

Delb H, Bublitz T, John R, Metzler B, Schumacher J (2013a) Waldschutzsituation 2012/2013 in Baden-Württemberg. AFZ-Der Wald 68:8-11

Delb H, Bublitz T, John R, Metzler B, Schumacher J (2013b) Waldschutzsituation 2012/2013 in Rheinland-Pfalz. AFZ-Der Wald 68:16-19

Douglas GC, Pliūra A, Dufour J, Mertens P, Jacques D, FernandezManjares J, Buiteveld J, Parnuta G, Tudoroiu M, Curnel Y, Thomasset M, Jensen V, Knudsen M, Foffova E, Chandelier A, Steenackers M (2013) Common ash (Fraxinus excelsior L.). In: Pâques LE (ed) Forest tree breeding in Europe: current state-ofthe-art and perspectives, Springer, pp 403-462

Enderle R, Peters F, Nakou K, Metzler B (2013) Temporal development of ash dieback symptoms and spatial distribution of collar rots in a provenance trial of Fraxinus excelsior. Eur J Forest Res 132:865876. doi:10.1007/s10342-013-0717-y

Gross A, Holdenrieder O, Pautasso M, Queloz V, Sieber TN (2014) Hymenoscyphus pseudoalbidus, the causal agent of European ash dieback. Mol Plant Pathol 15:5-21

Hadfield JD (2010) MCMC methods for multi-response generalized linear mixed models: the MCMCglmm R Package. J Stat Softw 33:1-22

Houle D (1992) Comparing evolvability and variability of quantitative traits. Genetics 130:195-204

Husson C, Scala B, Cael O, Frey P, Feau N, Ioos R, Marcais B (2011) Chalara fraxinea is an invasive pathogen in France. Eur J Plant Pathol 130:311-324

Husson C, Caël O, Grandjean JP, Nageleisen LM, Marçais B (2012) Occurrence of Hymenoscyphus pseudoalbidus on infected ash logs. Plant Pathol 61:889-895. doi:10.1111/j.1365-3059.2011.02578.x

Kirisits T, Freinschlag C (2012) Ash dieback caused by Hymenoscyphus pseudoalbidus in a seed plantation of Fraxinus excelsior in Austria. J Agric Ext Rural Dev 4:184-191. doi:10.5897/JAERD12.046

Kjær ED, Wellendorf H (1997) Variation in flowering and reproductive success in a Danish Picea abies (Karst.) seed orchard. Int J For Genet 4:181-188

Kjær ED, McKinney LV, Nielsen LR, Hansen LN, Hansen JK (2012) Adaptive potential of ash (Fraxinus excelsior) populations against the novel emerging pathogen Hymenoscyphus pseudoalbidus. Evol Appl 5:219-228. doi:10.1111/j.1752-4571.2011.00222.x

Kowalski T (2006) Chalara fraxinea sp. nov. associated with dieback of ash (Fraxinus excelsior) in Poland. For Pathol 36:264-270. doi:10. 1111/j.1439-0329.2006.00453.x

Kowalski T, Holdenrieder O (2009) Pathogenicity of Chalara fraxinea. For Pathol 39:1-7. doi:10.1111/j.1439-0329.2008.00565.x
Lenz H, Straßer L, Baumann M, Baier U (2012) Boniturschlüssel zur Einstufung der Vitalität von Alteschen. AFZ-Der Wald 67:18-19

Lindgren D, Mullin TJ (1998) Relatedness and status number in seed orchard crops. Can J For Res 28:276-283

Lygis V, Vasiliauskas R, Stenlid J (2005) Wood-inhabiting fungi in stems of Fraxinus excelsior in declining ash stands of northern Lithuania, with particular reference to Armillaria cepistipes. Scand J For Res 20:337-346

McKinney LV, Nielsen LR, Hansen JK, Kjær ED (2011) Presence of natural genetic resistance in Fraxinus excelsior (Oleaceae) to Chalara fraxinea (Ascomycota): an emerging infectious disease. Heredity 106:788-797. doi:10.1038/hdy.2010.119

McKinney LV, Thomsen IM, Kjær ED, Bengtsson SBK, Nielsen LR (2012) Rapid invasion by an aggressive pathogenic fungus (Hymenoscyphus pseudoalbidus) replaces a native decomposer (Hymenoscyphus albidus): a case of local cryptic extinction? Fungal Ecol 5:663-669

McKinney LV, Nielsen LR, Collinge DB, Thomsen IM, Hansen JK, Kjær ED (2014) The ash dieback crisis: genetic variation in resistance can prove a long term solution. Plant Pathol. doi:10.1111/ppa.12196

Metzler B, Enderle R, Karopka M, Töpfner K, Aldinger E (2012) Entwicklung des Eschentriebsterbens in einem Herkunftsversuch an verschiedenen Standorten in Süddeutschland. German J For Res (AFJZ) 183:168-180

Metzler B, Baumann M, Baier U, Heydeck P, Bressem U, Lenz H (2013) Bundesweite Zusammenstellung: Handlungsempfehlungen beim Eschentriebsterben. AFZ-Der Wald 68:17-20

Orlikowski LB, Ptaszek M, Rodziewicz A, Nechwatal J, Thinggaard K, Jung T (2011) Phytophthora root and collar rot of mature Fraxinus excelsior in forest stands in Poland and Denmark. For Pathol 41: 510-519

Pautasso M, Aas G, Queloz V, Holdenrieder O (2013) European ash (Fraxinus excelsior) dieback - a conservation biology challenge. Biol Conserv 158:37-49

Pliūra A, Lygis V, Suchockas V, Bartkevičius E (2011) Performance of twenty four European Fraxinus excelsior populations in three Lithuanian progeny trials with a special emphasis on resistance to Chalara fraxinea. Balt For 17:17-34

Poland TM, McCullough DG (2006) Emerald ash borer: invasion of the urban forest and the threat to North America's ash resource. J For 104:118-124

Queloz V, Grünig CR, Berndt R, Kowalski T, Sieber TN, Holdenrieder O (2011) Cryptic speciation in Hymenoscyphus albidus. For Pathol 41: 333-342. doi:10.1111/j.1439-0329.2010.00645.x

Roloff A, Pietzarka U (1997) Fraxinus excelsior Linné 1753. In: Schütt et al. (eds) Enzyklopädie der Holzgewächse, 7th edn, ecomed, Landsberg am Lech, pp 1-15

Schröter H, Delb H, John R, Metzler B (2010a) Waldschutzsituation 2009/2010 in Baden-Württemberg. AFZ-Der Wald 65:8-11

Schröter H, Delb H, Metzler B (2010b) Waldschutzsituation 2009/2010 in Rheinland-Pfalz. AFZ-Der Wald 65:16-17 
Skovsgaard JP, Thomsen IM, Skovgaard IM, Martinussen T (2010) Associations between symptoms of dieback in even-aged stands of ash (Fraxinus excelsior L.). For Pathol 40:7-18

Stener LG (2013) Clonal differences in susceptibility to the dieback of Fraxinus excelsior. Scand J For Res 28:1-12. doi:10.1080/ 02827581.2012.735699

Straw NA, Williams DT, Kulinich O, Gninenko YI (2013) Distribution, impact and rate of spread of emerald ash borer Agrilus planipennis
(Coleoptera: Buprestidae) in the Moscow region of Russia. Forestry 86:515-522. doi:10.1093/forestry/cpt031

Visscher PM, Hill WG, Wray NR (2008) Heritability in the genomics era-concepts and misconceptions. Nat Rev Genet 9:255-266. doi: $10.1038 /$ nrg2322

Zhao YJ, Hosoya T, Baral HO, Hosaka K, Kakishima M (2012) Hymenoscyphus pseudoalbidus, the correct name for Lambertella albida reported from Japan. Mycotaxon 122:25-41 